\title{
Preparation and hydration mechanism of low shrinkage railway sleeper concrete con- taining hot steaming steel slag
}

\author{
Xiaoping Tian ${ }^{1,2,3}$, Yongchao Zheng ${ }^{1}$, Changlong Wang ${ }^{3,4,5, *}$, Hidayati Bte Asrah $^{2, \dagger}$ and Xiaowei Cui ${ }^{6}$ \\ ${ }^{1}$ State Key Laboratory of Solid Waste Reuse for Building Materials, Beijing Building Materials Academy of Science Research, Beijing \\ 100041, China \\ ${ }^{2}$ Faculty of Engineering, Universiti Malaysia Sabah, Kota Kinabalu Sabah, 88400, Malaysia \\ ${ }^{3}$ School of Civil Engineering, Hebei University of Engineering, Handan Hebei Province, 056038, China \\ ${ }^{4}$ Jiangxi Key Laboratory of Mining Engineering, Jiangxi University of Science and Technology, Ganzhou Jiangxi Province 341000, China \\ ${ }^{5}$ Tianjin Sunenergy Sega Environmental Science \& Technology Co. Ltd, Tianjin 300000, China \\ ${ }^{6}$ Shaanxi Key Laboratory of Comprehensive Utilization of Tailings Resources, Shangluo University, Shangluo Shaanxi Province 726000 , China
}

Corresponding Author Email: ${ }^{*}$ baistuwong@139.com; †hidayati@ums.edu.my

\begin{abstract}
The cascade grinding technology was used to product cementitious materials with hot steaming steel slag (SS), iron ore tailings (IOT), granulated blast furnace slag (GBFS), cement clinker (CC) and flue gas desulfurization gypsum (FGDG). The effect of SS on the mechanical properties and autogenous shrinkage of railway sleeper concrete and the mechanism of SS inhibiting the autogenous shrinkage of railway sleeper concrete were studied by means of X-ray diffraction (XRD), flourier transform-infrared spectroscopy (FT-IR), and scanning electron microscope (SEM). The results show that the compressive strength of IOT railway sleeper concrete mixed with SS (SIRSC) is lower than that of IOT railway sleeper concrete unmixed with SS (UIRSC) at the same age. However autogenous shrinkage of SIRSC is significantly lower than that of UIRSC, autogenous shrinkage value of SIRSC at $28 \mathrm{~d}$ was $230 \times 10^{-6}$, while that of UIRSC was $593 \times 10^{-6}$. The hydration mechanism analysis shows that the hydration expansion of a small amount of inert $\mathrm{f}-\mathrm{CaO}$ and $\mathrm{f}-\mathrm{MgO}$ phase contained in the $\mathrm{SS}$ is the main expansion source to restrain the autogenous shrinkage of SIRSC. The $\mathrm{f}-\mathrm{CaO}$ and $\mathrm{f}-\mathrm{MgO}$ phases are highly dispersed after superfine grinding $\mathrm{SS}$ is mixed with concrete. In the middle and later stage of concrete hardening, the synergistic growth of ettringite (AFt) and C-S-H gels inhibits the autogenous shrinkage of SIRSC and improves the mechanical properties.
\end{abstract}

Keywords: hot steaming steel slag; railway sleepers concrete with iron ore tailings; autogenous shrinkage; ettringite

Received: February-06-2019, Accepted: March-13-2019, https://doi.org/10.14447/jnmes.v22i2.a09

\section{INTRODUCTION}

Steel Slag (SS) is a main solid waste in the iron and steel industry, and its treatment technologies include the hot-SS splashing method, the air-granulation method, the drum-type method, the granulation wheel method, and the tank-type hot-SS disintegrating method, etc. [1]. Due to SS's characteristics of poor stability, high rigidity, and hard-to-break, its utilization rate has been relatively low for a long time [2]. The tank-type hot-SS disintegrating technique makes use of the uneven cold shrinkage of liquid hot-SS when it meets cold water to disintegrate the large chunks of SS, in the disintegrated SS particles, particles with a particle size of less than $20 \mathrm{~mm}$ account for more than $60 \%$, and the contents of free calcium oxide $(\mathrm{f}-\mathrm{CaO})$ and free magnesium oxide (f-MgO) in the SS are both less than $2 \%$, and this can improve the stability of SS and promote its utilization in the field of building materials. Teng et al [3] studied the effects of superfine ground SS on the durability and mechanical properties of SS cementing material, and found that the ground SS can accelerate the hydration reaction of the system. Wang et al. [4-6] studied the effect of hightemperature curing on the early hydration characteristics of SS cementing material, and found that the hydration reaction of SS and the generation of hydration products of SS had been both accelerated at high temperatures, and the pore structure of the cementing material had been optimized. Takashima [7] excited SS at high temperatures $\left(800 \sim 1450{ }^{\circ} \mathrm{C}\right.$ ) so that the $\gamma-\mathrm{C}_{2} \mathrm{~S}$ (low gelation performance) in SS could be transformed into $\alpha-\mathrm{C}_{2} \mathrm{~S}$ or $\alpha^{\prime}-\mathrm{C}_{2} \mathrm{~S}$ (high gelation performance), and the SS contained more $\alpha-\mathrm{C}_{2} \mathrm{~S}$ or $\alpha^{\prime}-\mathrm{C}_{2} \mathrm{~S}$ after quenching. Such modified SS can be used as highly active admixture in the concrete and cement of architectural engineering projects.

Autogenous shrinkage of concrete refers to the phenomenon that under constant temperature and humidity, since the free water in the pores is continuously consumed by the hydrating cementing material and the internal humidity is reduced, and thus causing the volume shrinkage of the concrete. The autogenous shrinkage of concrete has become an important problem to be solved urgently in the production and application of high-performance concrete [8]. Lepage et al. [9] found that high-performance concrete with low water-binder ratio will self-dry with the hydration process, resulting in certain autogenous shrinkage of concrete in the early stage, and the incorporation of ultrafine mineral admixtures will cause the concrete to shrink even more [10]. Railway sleeper concrete (RSC) is a kind of prestressed concrete, due to its large ratio of autogenous shrinkage, large prestress loss will be generated, and it'll affect the safety of the sleepers [11]. Zheng et al. [12] used iron ore tailings (IOT) to prepare coarse aggregate-free RSC, which has become an important direction in the field of highperformance concrete. This kind of concrete is prepared from iron ore tailings (IOT), granulated blast furnace slag (GBFS), cement clinker (CC), and fuel gas desulfurized gypsum (FGDG), and grinding IOT was used as the aggregates of the concrete. Since coarse aggregate was not used in the concrete, the ratio of autogenous shrinkage of the con- 


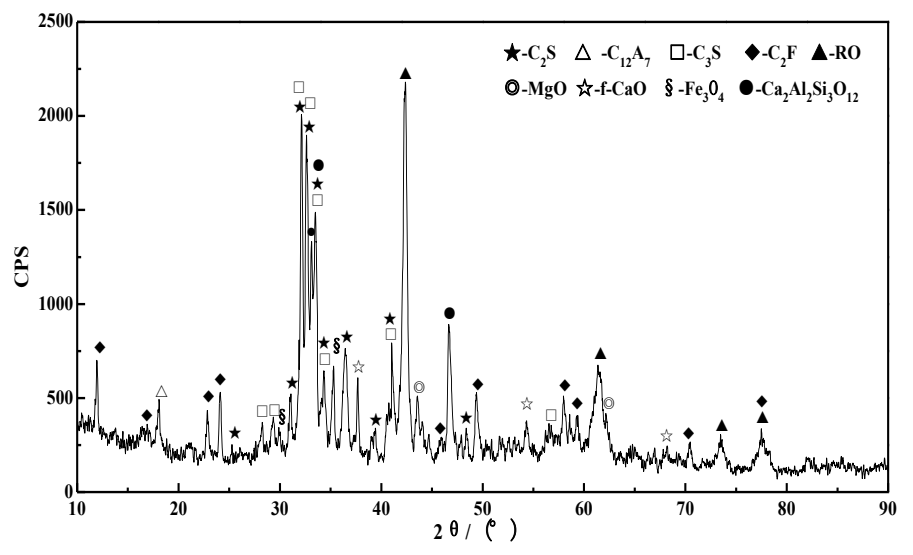

Figure 1. XRD spectra of SS

crete was relatively large. Aiming at the problem of large ratio of autogenous shrinkage of the IOT railway sleeper concrete (IRSC), this study adopts the method of incorporating SS powder to study its effect on suppressing the autogenous shrinkage of IRSC, and it applies X-ray diffraction (XRD), flourier transform-infrared spectroscopy (FT-IR), and scanning electron microscope (SEM) and other test methods to analyze the mechanism of the effect of SS on suppressing the autogenous shrinkage of IRSC, which is of great significance for solving the excessive ratio of autogenous shrinkage of the coarse aggregate-free IOT concrete and the resulted prestress loss of railway sleeper concrete (RSC).

\section{Materials and methods}

\subsection{Materials}

(1) SS. The main chemical components are listed in Table 1. SS with a particle size between $0.15 \sim 4.57 \mathrm{~mm}$ was adopted in the experiment. Its main mineral compositions are $\mathrm{C}_{2} \mathrm{~S}, \mathrm{C}_{3} \mathrm{~S}, \mathrm{C}_{2} \mathrm{~F}$, and $\mathrm{RO}$ phase (solid solutions of $\mathrm{MgO}, \mathrm{FeO}$, and $\mathrm{MnO}$ ), as shown in Fig. 1. Due to the slow cooling rate of $\mathrm{SS}$, the $\mathrm{C}_{2} \mathrm{~S}$ and $\mathrm{C}_{3} \mathrm{~S}$ in the slag are much less active than those in the $\mathrm{CC}$; while for $\mathrm{C}_{2} \mathrm{~S}$, during the slow cooling process, the metastable $\beta-C_{2} S$ will turn to stable $\gamma-C_{2} S$, and the $C_{3} S$ will turn to a stable state during the cooling process as well. The basicity coefficient of SS: $\mathrm{M}=\mathrm{W}(\mathrm{CaO}) /\left[\mathrm{W}\left(\mathrm{SiO}_{2}\right)+\mathrm{W}\left(\mathrm{P}_{2} \mathrm{O}_{5}\right)\right]=2.78$, which means the $\mathrm{SS}$ is high alkalinity slag $(\mathrm{M}>2.5)$. According to $\mathrm{YB} / \mathrm{T} 140-$ 2009 Methods of Chemical Analysis for Steel Slag, with ethylene glycol as the extractant, the content of $\mathrm{f}-\mathrm{CaO}$ was measured by the EDTA complexometric titration; in addition, the $\mathrm{SO}_{3}$ content was $0.42 \%$. These numbers met the requirements listed in the GB/T20491-2006 Steel Slag Powder Used for Cement and Concrete that the basicity should not be less than 1.8, the content of $\mathrm{f}-\mathrm{CaO}$ should not be more than $3 \%$, and the content of $\mathrm{SO}_{3}$ should not be more than $3 \%$. Neither

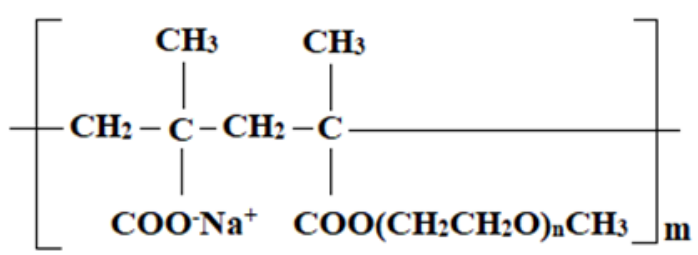

Figure 2. Molecular structure of PC water-reducers

YB/T 140-2009 nor GB/T20491-2006 have stipulated the measurement or the content of free magnesium oxide (f-MgO), but it has a great impact on the application of SS in the building materials, so this study took ammonium nitrate-ethanol as the extractant and the $\mathrm{f}-\mathrm{MgO}$ content was determined to be $0.81 \%$.

(2) IOT. The chemical compositions are listed in Table 1. The content of $\mathrm{SiO}_{2}$ in the IOT reached $72.12 \%$ (mass fraction, the same below), the IOT are high silicon content IOT, and their main mineral components are quartz with a small amount of hornblende, anorthite and chlorite, etc. In mass fraction, tailings with a particle size between $0.074 \mathrm{~mm}$ and $0.16 \mathrm{~mm}$ were about $40.62 \%$, and those with a particle size larger than $0.63 \mathrm{~mm}$ accounted for less than $1 \%$, about $10.43 \%$ of the tailings have a particle size of less than $0.043 \mathrm{~mm}$ (see Table 2 for the size fraction of the IOT).

(3) CC. The mineral compositions of CC are mainly $\mathrm{C}_{3} \mathrm{~S}, \mathrm{C}_{2} \mathrm{~S}, \mathrm{C}_{3} \mathrm{~A}$, and $\mathrm{C}_{4} \mathrm{FA}$, its chemical compositions are listed in Table 1 .

(4) GBFS. The chemical compositions are listed in Table 1. Waterquenched GBFS with a particle size between $0.1 \sim 0.5 \mathrm{~mm}$ was adopted. The slag has a low crystallinity and basically exhibits the glassy state.

(5) FGDG. Thermal power plant FGDG was adopted, the contents of $\mathrm{CaO}$ and $\mathrm{SO}_{3}$ in the FGDG were relatively high, followed by $\mathrm{SiO}_{2}$, $\mathrm{MgO}$ and $\mathrm{Al}_{2} \mathrm{O}_{3}$, the fineness $(\geq 0.08 \mathrm{~mm})$ is $16 \%$, and its chemical compositions are shown in Table 1.

(6) Other materials. Crushed limestone was adopted for the coarse aggregates of the concrete; the particle size was $5 \sim 25 \mathrm{~mm}$. Polycarboxylic acid (PC) was adopted as the superplasticizer, its molecular structure is shown in Fig. 2.

\subsection{Methods}

\subsubsection{Preparation of the concrete}

Two schemes shown below were adopted to pretreat the raw materials and prepare the cementing materials.

Firstly, the IOT was sieved; then according to the ratio of 20: 13: 13: 4, IOT (particle size of $-0.074 \mathrm{~mm}$ ), GBFS, CC and FGDG were subject to gradient mixed grinding. The laboratory 5-kg type SM $\Phi 500 \times 500$ small ball mill was adopted to grind the materials. The IOT were subject to the first-stage grinding and the ground IOT (specific surface area was $345 \mathrm{~m}^{2} \cdot \mathrm{kg}^{-1}$ ) were mixed with the raw GBFS according to the original proportion and both were ground together; then the second-stage mixture (specific surface area was $540 \mathrm{~m}^{2} \cdot \mathrm{kg}^{-1}$ )

Table 1. Chemical composition of raw materials (wt.\%)

\begin{tabular}{|c|c|c|c|c|c|c|c|c|c|c|c|c|}
\hline Materials & $\mathrm{SiO}_{2}$ & $\mathrm{Al}_{2} \mathrm{O}_{3}$ & $\mathrm{Fe}_{2} \mathrm{O}_{3}$ & $\mathrm{FeO}$ & $\mathrm{MgO}$ & $\mathrm{CaO}$ & f- $\mathrm{CaO}$ & f- MgO & $\mathrm{Na}_{2} \mathrm{O}$ & $\mathrm{K}_{2} \mathrm{O}$ & $\mathrm{SO}_{3}$ & LOI \\
\hline SS & 12.22 & 6.84 & 14.53 & 11.81 & 11.00 & 35.82 & 1.23 & 0.81 & 1.54 & 0.12 & 0.42 & 5.04 \\
\hline IOT & 72.12 & 3.04 & 12.62 & 3.44 & 1.13 & 2.96 & - & - & 0.17 & 0.14 & 0.16 & 3.06 \\
\hline GBFS & 32.70 & 15.40 & 0.40 & 一 & 8.97 & 38.79 & - & - & 0.02 & 0.35 & 1.93 & 0.76 \\
\hline FGDG & 3.16 & 1.35 & 0.47 & 0.09 & 7.49 & 33.38 & - & - & 0.10 & 0.24 & 45.70 & 8.28 \\
\hline $\mathrm{CC}$ & 22.50 & 4.86 & 3.43 & 0.02 & 0.83 & 66.30 & - & - & 0.11 & 0.08 & 0.31 & 0.96 \\
\hline
\end{tabular}

Table 2 Particle size distribution of IOT (wt.\%)

\begin{tabular}{|c|c|c|c|c|c|c|}
\hline \multirow{2}{*}{ Material } & \multicolumn{6}{|c|}{ Particle size $/ \mathrm{mm}$} \\
\hline & +0.63 & $0.315 \sim 0.63$ & $0.16 \sim 0.315$ & $0.074 \sim 0.16$ & $0.043 \sim 0.074$ & -0.043 \\
\hline IOT & 0.06 & 5.25 & 30.90 & 40.62 & 13.66 & 10.43 \\
\hline
\end{tabular}




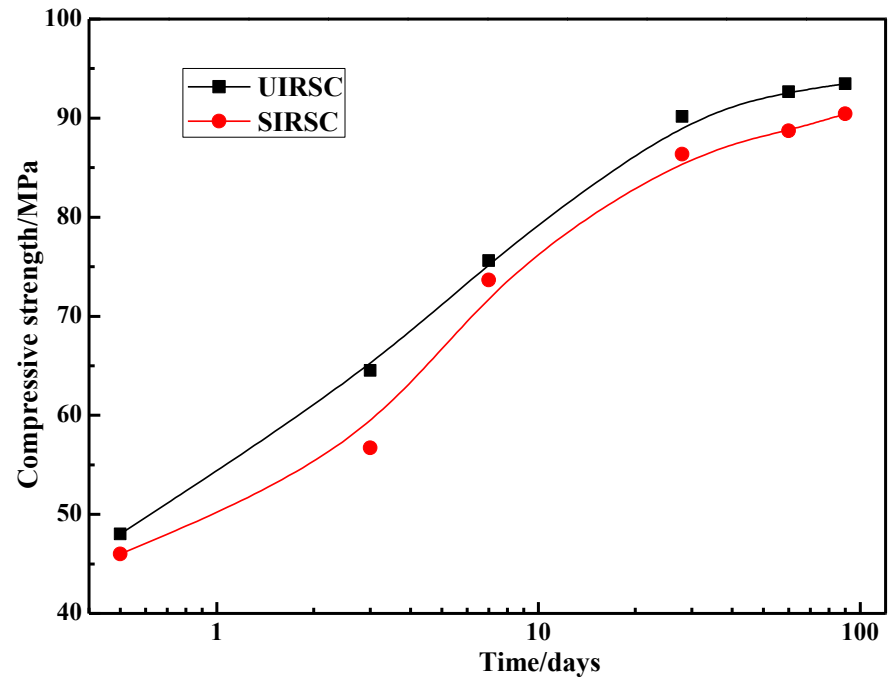

Figure 3. The effect of mechanical properties of SS for IRSC

was obtained and again mixed with the CC and FGDG according to the original proportion and all materials were subject to the third-stage grinding, then the third-stage mixture (specific surface area was 652 $\mathrm{m}^{2} \cdot \mathrm{kg}^{-1}$ ) was obtained and taken as the Group-I cementitious materials for the RSC.

The ground SS powder with a specific surface area of $624 \mathrm{~m}^{2} \cdot \mathrm{kg}^{-1}$ was mixed with the third-stage mixture (specific surface area was 652 $\left.\mathrm{m}^{2} \cdot \mathrm{kg}^{-1}\right)$ at a ratio of 1:4 to obtain Group-II cementitious materials for the RSC.

IOT of original particle size $(\geq 0.074 \mathrm{~mm})$ that were taken as the aggregates were mixed with cementing materials I and II at a ratio of 1:1 respectively, and the water-binder ratio was 0.23 , moreover, superplasticizer of $0.4 \%$ of the total cementitious materials I was added respectively, wherein the IRSC prepared by cementitious materials I was marked as UIRSC, and the IRSC prepared by cementitious materials II was marked as SIRSC.

After that, the cement slurry was fully stirred and injected into a 100 $\mathrm{mm} \times 100 \mathrm{~mm} \times 100 \mathrm{~mm}$ mold for strength testing. At the same time, prism-shaped test pieces of the size $100 \mathrm{~mm} \times 100 \mathrm{~mm} \times 515 \mathrm{~mm}$ were prepared as well for the test of the autogenous shrinkage of the concrete. Copper measuring heads were embedded at both ends of the test pieces before the test. The curing conditions were the same as the production of common RSC: after the test pieces were cast and stood for 4 hours, within $3 \mathrm{~h}$ the temperature was heated to $55{ }^{\circ} \mathrm{C}$ (the heating rate was not faster than $15^{\circ} \mathrm{C} / \mathrm{h}$ ), and the test pieces were stood at $(55 \pm 2){ }^{\circ} \mathrm{C}$ for 3 hours, and then the temperature was cooled to room temperature (the cooling rate was not faster than $15^{\circ} \mathrm{C} / \mathrm{h}$ ). After the steam curing, the test pieces were demolded and cured under the standard curing conditions, and the mechanical properties and autogenous shrinkage of the different-stage concrete at 12 hours (demold time), $3 \mathrm{~d}, 7 \mathrm{~d}, 28 \mathrm{~d}$, $60 \mathrm{~d}$, and $90 \mathrm{~d}$ were tested respectively.

\subsubsection{Performance characterization}

The particle size of the ground materials was analyzed by the MASTER SIZER 2000 laser particle size analyzer (test range: 0.02 2000.00 $\mu \mathrm{m})$, with ethanol as the dispersant, the distribution of the particle size of the powder samples was tested according to GB/T19077.1-2008 the Particle Size Analysis-Laser Diffraction Methods; the specific surface area of the ground materials was measured by the SSA-3200 dynamic specific surface area analyzer; at the specified ages of $12 \mathrm{~h}, 3 \mathrm{~d}, 7 \mathrm{~d}, 28 \mathrm{~d}$, 60d, and 90d, according to GB/T50081-2002 Standard for Test Method

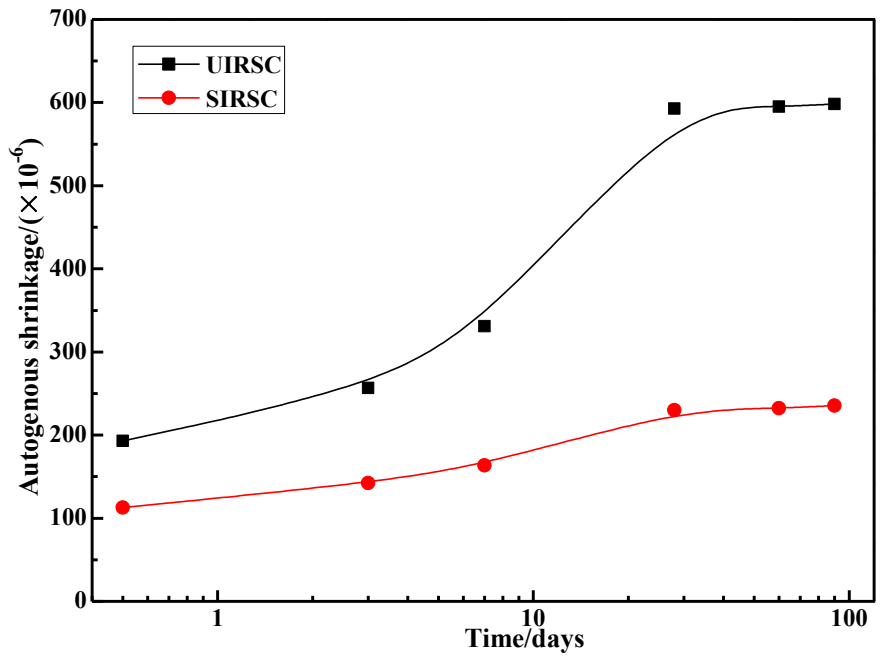

Figure 4. The effect of autogenous shrinkage of SS for IRSC

of Mechanical Properties on Ordinary Concrete, the mechanical properties of the samples were tested; and according to GB/T50082-2009 Standard for Test Methods of Long-Term Performance and Durability of Ordinary Concrete, the value of autogenous shrinkage of concrete was tested.

In order to avoid the interference of the compositions of the tailings on the microscopic analysis after the addition of fine aggregates, pure slurry samples were prepared using the cementing materials for the microscopic test analysis. Rigaku D/MAX-RC 12KW target-turning anode diffractometer was adopted for the XRD analysis; NEXUS70 Fourier infrared spectrometer was adopted for the infrared spectroscopic analysis; and the ZEISS SUPRA ${ }^{\mathrm{TM}_{5}} 55$ field emission scanning electron microscope (FE-SEM) was adopted for microstructure analysis.

\section{RESULTS AND DISCUSSION}

\subsection{Effects of SS on the concrete performance}

Effects of SS of different ages on the mechanical properties of the two groups of RSC are shown in Fig. 3.

Fig. 3 compares the values of the compressive strength of two groups of RSC: SIRSC (SS added) and UIRSC (no SS added) at $12 \mathrm{~h}, 3 \mathrm{~d}, 7 \mathrm{~d}$, $28 \mathrm{~d}, 60 \mathrm{~d}$, and $90 \mathrm{~d}$ under the same conditions. It can be seen that the values of the compressive strength of concrete with and without SS were not much different, and the laws of the development of strength were basically the same.

For the RCS prepared by cementitious materials with and without $\mathrm{SS}$, the $12 \mathrm{~h}$ compressive strength was $48.01 \mathrm{MPa}$ and $45.98 \mathrm{MPa}$, respectively, both were larger than $45 \mathrm{MPa}$; the values of $3 \mathrm{~d}$ compressive strength were both larger than $58 \mathrm{MPa}$ and the values of $28 \mathrm{~d}$ compressive strength were both larger than $80 \mathrm{MPa}$, these values can meet the strength requirements of RSC. The strength of SIRSC was slightly lower than that of UIRSC at the same age, it's because the $\mathrm{C}_{3} \mathrm{~S}$ (faster hydration in early stage) content added in the SS was smaller and the $\mathrm{C}_{2} \mathrm{~S}$ (slower hydration) content was larger. The incorporation of SS powder slows down the early hydration rate of the concrete, and the larger the proportion of added SS powder, and slower the hydration rate of the concrete, and thus the values of the early compressive strength of the concrete $(12 \mathrm{~h}$ and $3 \mathrm{~d})$ are lower $[13,14]$. In the Fig. 3, the differences between the $3 \mathrm{~d}$ and $28 \mathrm{~d}$ compressive strength of SIRSC and UIRSC were $25.63 \mathrm{MPa}$ and $32.01 \mathrm{MPa}$, respectively, indicating that the incorporation of SS powder is conducive to the increase of the 


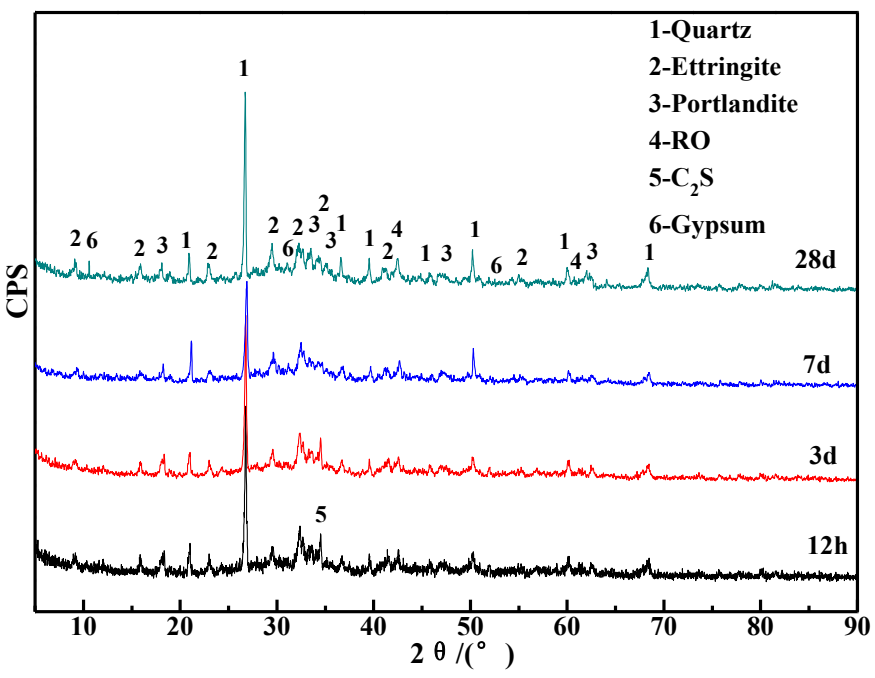

Figure 5. XRD patterns of the SIRSC paste blocks at different ages

strength of the concrete in the later period. When the amount of SS powder is too large, the $\mathrm{CC}$ content in the mixture is reduced correspondingly, so the amount of C-S-H gels is reduced, and thereby the strength of SIRSC is slightly lower than that of UIRSC at the same age [14].

The autogenous shrinkage of concrete is an important indicator for the volume stability of RSC. This paper tests the autogenous shrinkage of the concrete prepared by two groups of cementitious materials, and the changes of the autogenous shrinkage of SIRSC and UIRSC at $12 \mathrm{~h}$, $3 \mathrm{~d}, 7 \mathrm{~d}, 28 \mathrm{~d}, 60 \mathrm{~d}$ and $90 \mathrm{~d}$ are shown as Fig. 4 . It can be seen from the Fig. 4 that as the concrete age increases, it can be clearly seen that the slope of the curve of autogenous shrinkage of SIRSC was lower, the trend of the entire curve was smooth; while for the curve of autogenous shrinkage of UIRSC, the slope increased fast since $12 \mathrm{~h}$, meanwhile for the SIRSC test pieces, the values of the autogenous shrinkage at each age were lower than those of ordinary RSC [15], indicating that the incorporation of SS powder has a very obvious effect on suppressing the autogenous shrinkage of RSC. With the increase of the concrete age, the value of the autogenous shrinkage of UIRSC at $12 \mathrm{~h}$ was $193 \times 10^{-6}$, the value of the autogenous shrinkage at $28 \mathrm{~d}$ was $593 \times 10^{-6}$, after that, the trend of the autogenous shrinkage of UIRSC was smooth and the change was slow. The value of autogenous shrinkage of SIRSC at $12 \mathrm{~h}$ was $112 \times 10^{-6}$, and the $28 \mathrm{~d}$ value was $230 \times 10^{-6}$, which was only $39.18 \%$ of the shrinkage value of ordinary concrete at $28 \mathrm{~d}$, indicating that the incorporation of SS powder can effectively reduce the autogenous shrinkage of RSC.

\subsection{Phase composition and morphology of hardened slurry test blocks}

Fig. 5 is the XRD spectrum of SIRSC test pieces prepared by paste blocks after curing for $12 \mathrm{~h}, 3 \mathrm{~d}, 7 \mathrm{~d}$, and $28 \mathrm{~d}$. The main mineral phases are quartz, ettringite $(\mathrm{AFt}), \mathrm{Ca}(\mathrm{OH})_{2}, \mathrm{C}_{2} \mathrm{~S}$, RO phase and gypsum.

Quartz is a mineral component of IOT, and RO phase is a mineral component of SS, which does not participate in the hydration reaction. The diffraction peak of AFt began to appear at $12 \mathrm{~h}$ after pouring, then with the increase of curing age, the strength enhanced constantly, indicating that the early hydration reaction had begun. The $\mathrm{C}_{2} \mathrm{~S}$ and $\mathrm{C}_{3} \mathrm{~S}$ in $\mathrm{CC}$ and activated SS reacted with FGDG to produce the AFt. Due to the fast hydration rate of $\mathrm{C}_{3} \mathrm{~S}$, the reaction was complete in the early stage of hydration, and no diffraction peak had appeared in the XRD spectrum. While for $\mathrm{C}_{2} \mathrm{~S}$, the hydration rate was relatively slow, so the

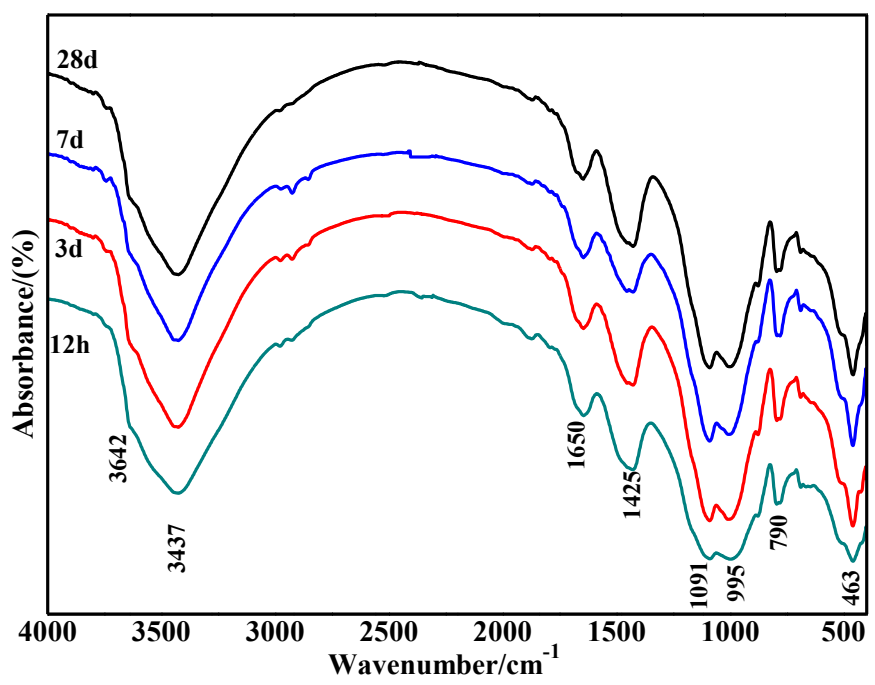

Figure 6. FT-IR spectra of $\mathrm{t}$ of the SIRSC paste blocks at different ages

diffraction peaks in the XRD spectrum at $12 \mathrm{~h}$ and $3 \mathrm{~d}$ were clearly visible. With the progress of the hydration reaction, the diffraction peaks of $\mathrm{C}_{2} \mathrm{~S}$ gradually weakened, and the diffraction peaks of $\mathrm{AFt}$ gradually increased. At the early stage of hydration, the activated SS power and the $\mathrm{C}_{2} \mathrm{~S}$ and $\mathrm{C}_{3} \mathrm{~S}$ in $\mathrm{CC}$ reacted and generated hydration products $\mathrm{Ca}(\mathrm{OH})_{2}$ and C-S-H gels. At the same time, $\mathrm{f}-\mathrm{CaO}$ in SS was hydrated to produce $\mathrm{Ca}(\mathrm{OH})_{2}$. The $\mathrm{Ca}(\mathrm{OH})_{2}$ produced in the early stage had a low crystallinity and the crystal grains were very tiny. The $\mathrm{Ca}(\mathrm{OH})_{2}$ reacted fast with the ultra-fine SS powder, the GBFS powder and the IOT particles in the system [16], and most of them were consumed; but with the increase of the concrete age, in the system, the content of reactive $\mathrm{SiO}_{2}$ in the ultra-fine GBFS powder and the nano IOT particles decreased, and the rate of $\mathrm{Ca}(\mathrm{OH})_{2}$ generation is greater than the rate of consumption, resulting in accumulation of $\mathrm{Ca}(\mathrm{OH})_{2}$. With the increase of the age of hydration, the crystallinity of $\mathrm{Ca}(\mathrm{OH})_{2}$ increased, the particle size grew larger, and the diffraction enhanced, causing volume expansion [17], and thereby resulting in that the diffraction peak of $\mathrm{Ca}(\mathrm{OH})_{2}$ at $28 \mathrm{~d}$ was enhanced. In the figure, a wide "convex hull" shaped background appeared between $25^{\circ}$ and $35^{\circ}$, indicating that in the hardened gelled materials, there were substances such as low-crystallinity or amorphous C-S-H gels. In the system, the generation of C-S-H gels mainly had two ways: the continued hydration of residual $\mathrm{C}_{2} \mathrm{~S}$ and $\mathrm{C}_{3} \mathrm{~S}$, and the secondary pozzolanic reaction of the active silico-aluminum materials. Fig. 3 shows that the compressive strength of SIRSC increased by $87.82 \%$ from $12 \mathrm{~h}$ to $28 \mathrm{~d}$, thereby it can be inferred that during the curing from $3 \mathrm{~d}$ to $28 \mathrm{~d}$, a large amount of new hydration products $\mathrm{C}-\mathrm{S}-\mathrm{H}$ gels were generated in the process.

Fig. 6 shows the comparison of the FT-IR spectra of the SIRSC paste blocks at $12 \mathrm{~h}, 3 \mathrm{~d}, 7 \mathrm{~d}$, and $28 \mathrm{~d}$; the graphs of test pieces of different ages were similar, basically showing the same characteristic absorption band, and all absorption peaks moved in the smaller wave number direction. The absorption peak at $463 \mathrm{~cm}^{-1}$ was the bending vibration of the Si-O bond; the absorption peak at $790 \mathrm{~cm}^{-1}$ was the absorption vibration of quartz. The absorption peak at $995 \mathrm{~cm}^{-1}$ was caused by the asymmetrical vibration of $\mathrm{Si}-\mathrm{O}$ bond in the $\left[\mathrm{SiO}_{4}\right]$ structure, it is the characteristic peak of C-S-H gels. The absorption band at $1425 \mathrm{~cm}^{-1}$ was the asymmetrical stretching vibration band of $\mathrm{CO}_{3}{ }^{2-}$, which might be caused due to the carbonization of the sample during the preparation process. The absorption band at $1650 \mathrm{~cm}^{-1}$ was the bending vibration of the $\mathrm{O}-\mathrm{H}$ bond in the water. The band at $3437 \mathrm{~cm}^{-1}$ was the stretching vibration of the hydration product $\mathrm{C}-\mathrm{S}-\mathrm{H}$ gels, indicating that the hy- 

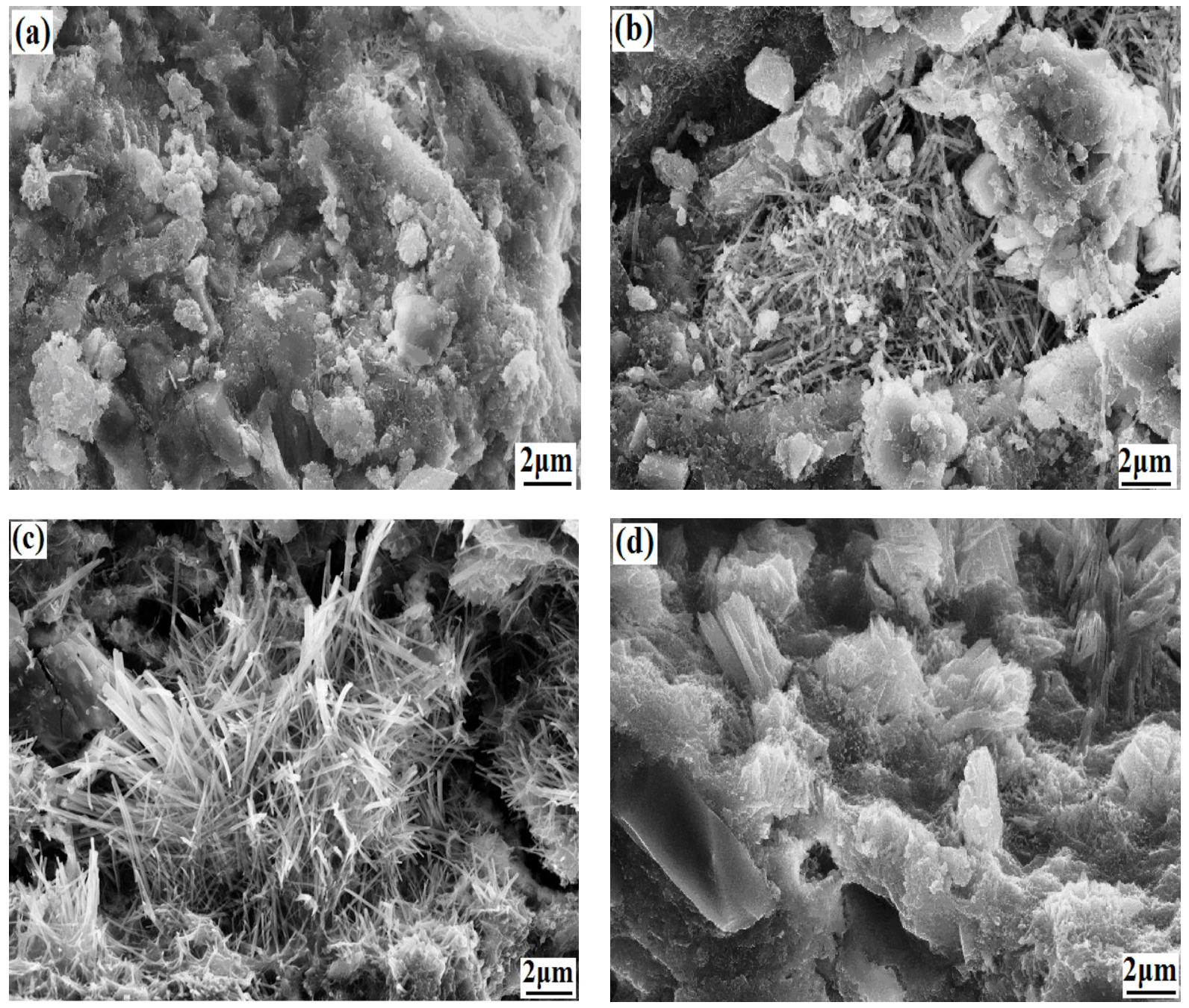

Figure 7. FE-SEM images of the SIRSC pure slurry test blocks at different ages. (a) cured for $12 \mathrm{~h}$, (b) cured for $3 \mathrm{~d}$, (c) cured for $7 \mathrm{~d}$, (d) cured for $28 \mathrm{~d}$

dration product $\mathrm{C}-\mathrm{S}-\mathrm{H}$ gels were continuously generated as the age increased. As can be seen from the figure, the absorption peak at 3642 $\mathrm{cm}^{-1}$ which reflected the stretching vibration of the $\mathrm{O}-\mathrm{H}$ bond is not obvious, this is because the hydroxyl groups in the AFt and C-S-H gels are not typical hydroxyl groups, they have no clear boundaries with the hydrogen bonds and molecular bonds in crystal water, so they are masked by the peak of the crystal water at $3437 \mathrm{~cm}^{-1}$. However, since the water in AFt is mostly crystal water, its absorption peak overlapped with the absorption peak of the constitution water of the C-S-H gels at $3437 \mathrm{~cm}^{-1}$, showing a strong absorption peak. The strong absorption band at $1091 \mathrm{~cm}^{-1}$ was asymmetric stretching vibration of the S-O bond, and its vibration peak was strengthened and sharpened with the passing of the curing time. For test block that had been cured for $12 \mathrm{~h}$, there was obvious absorption peak at $1091 \mathrm{~cm}-1$, indicating that $\mathrm{AFt}$ had ready been generated after $12 \mathrm{~h}$ hydration; and after $3 \mathrm{~d}$ hydration, a reasonable quantity of AFt had been generated; it can be seen that the formation rate of $\mathrm{Aft}$ was quite fast, which is consistent with the XRD results shown in Fig. 3.

Fig. 7 are FE-SEM images of the SIRSC paste block at $12 \mathrm{~h}, 3 \mathrm{~d}, 7 \mathrm{~d}$, and 28 d. From Fig. 7(a), we can see the micro morphology of the hardened paste sample when the gelled material had been hydrated for $12 \mathrm{~h}$. The main hydration products of the test block after steam curing were mainly low-crystallinity or amorphous C-S-H gels and a small amount of fibrous hydration product $\mathrm{AFt}$, indicating that the test block had undergone certain hydration reaction in $12 \mathrm{~h}$. The $\mathrm{Ca}^{2+}$ and $\mathrm{Al}^{3+}$ in $\mathrm{CC}$, GBFS and SS reacted with the FGDG in the alkaline solution and produced the AFt, which was conducive to obtaining hardened gelled materials with higher structural strength, and the expansion performance of AFt can partially inhibit the autogenous shrinkage of the concrete $[18,19]$. It can be seen from Fig. 7(b) that after $3 \mathrm{~d}$ hydration, a large amount of C-S-H gels and the needle-shaped AFt that overlapped with each other had been formed, the C-S-H gels and the AFt together constituted a spatial network structure, which is conductive for the earlystage strength of the test blocks. Compared with Fig. 7(a), the compactness of the gel system had been significantly improved, and the increase of the compactness of the C-S-H gel system had made the surface of the unreacted larger SS and IOT particles be wrapped with hydration products, while the $\mathrm{f}-\mathrm{CaO}$ and $\mathrm{f}-\mathrm{MgO}$ in the SS were slowly hydrated and produced $\mathrm{Ca}(\mathrm{OH})_{2}$ and $\mathrm{Mg}(\mathrm{OH})_{2}$, resulting in the shrinkage characteristics of $\mathrm{CC}$ during the hydration process and the corresponding volume expansion [20]. Fig.7(c) shows the paste block at $7 \mathrm{~d}$, it can be seen that the amount of the needle-shaped AFt crystals with better morphology had further increased, they interlaced with each other and distributed among C-S-H gels, the gaps between large parti- 


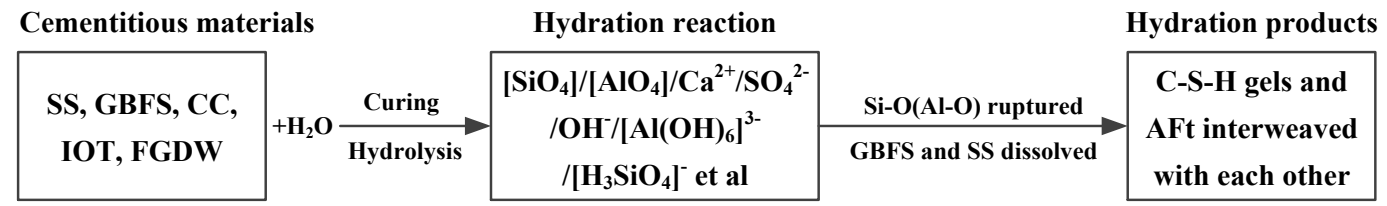

Figure 8. Schematic diagram of the hydration reaction mechanism of cementitious materials for SIRSC [21, 22]

cles were reduced, and the compactness of the sample was further improved. Fig. 7(d) shows the paste block at 28d, the AFt crystals had been completely encapsulated and wrapped by the C-S-H gels. As the hydration products were produced in large amount, the C-S-H gels phase was generated continuously in the hydration process and filled in the gaps, so larger gaps were reduced and the structure of the slurry had become denser. Larger SS particles were also wrapped in the hydration products and cemented into a whole, thereby the mechanical properties of the hardened slurry sample had been improved.

\subsection{Discussion}

From the above tests and microscopic analysis results, it can be seen that the CC system had been mixed with powders of IOT, GBFS, SS, FGDG and other solid wastes that weighted $74 \%$ of the total amount, and the produced SIRSC cementitious materials has the characteristics of high activity and low shrinkage. The ultra-fine particle size and highly-dispersed SS fine powder have the dual functions of constant expansion to compensate for shrinkage, and continuous improving the strength of the concrete.

Fig. 8 shows the mechanism of the hydration reaction of the SIRSC cementitious materials, and Fig. 9 gives a model for the hydration reaction of the SIRSC cementitious materials. In the middle and late stages of concrete hardening, the synergistic formation of AFt and C-S-H gels in the system also played an important role in suppressing the autogenous shrinkage and enhancing the strength of the SIRSC. There is a large amount of ultra-fine GBFS particles in the cementing system of coarse aggregate-free IOT concrete. GBFS are glassy materials connected by a large number of $\left[\mathrm{SiO}_{4}\right]$ and $\left[\mathrm{AlO}_{4}\right]$. The $\left[\mathrm{SiO}_{4}\right]$ and $\left[\mathrm{AlO}_{4}\right]$ were disorderly arranged; cations such as $\mathrm{Ca}^{2+}$ and $\mathrm{Mg}^{2+}$ were disorderly distributed around the $\left[\mathrm{SiO}_{4}\right]$ and $\left[\mathrm{AlO}_{4}\right]$ to balance the charge. When the GBFS in the cementing material met water, under the polarizing action of $\mathrm{OH}^{-}$, the Si-O bond, Al-O bond, $\mathrm{Ca}-\mathrm{O}$ bond and $\mathrm{Mg}-\mathrm{O}$ bond on the surface of the glassy GBFS would break and dissolve into the water in the forms of $\left(\mathrm{H}_{2} \mathrm{SiO}_{4}\right)^{2-},\left(\mathrm{H}_{3} \mathrm{SiO}_{4}\right)^{-},\left(\mathrm{H}_{4} \mathrm{AlO}_{4}\right)^{-}$and $\mathrm{Ca}(\mathrm{Mg})^{2+}$. In the alkaline environment, the $\mathrm{OH}^{-}$in the solution can not only destroy the $\mathrm{Ca}-\mathrm{O}$ and $\mathrm{Mg}-\mathrm{O}$ bonds, but also can break a considerable number of Si-O and Al-O bonds; while on the surface of the GBFS, hydration products were quickly formed by C-S-H, C-A-H and C-A-S$\mathrm{H}$ with lower $\mathrm{Ca} / \mathrm{Si}$ ratios. Pozzolanic reaction also occurred on the surface of the low-crystallinity IOT and SS particles after their mechanical properties had been chemically activated, the reaction consumed the $\mathrm{Ca}(\mathrm{OH})_{2}$ in the cementing material system, forming hydration products and further promoting the hydration of CC. When there's gypsum in the system, the reaction shown in formula (1) would occur:

$$
\begin{aligned}
2 \mathrm{H}_{3} \mathrm{AlO}_{4}{ }^{2-}+3 \mathrm{Ca}^{2+}+3 \mathrm{CaSO}_{4} \cdot 2 \mathrm{H}_{2} \mathrm{O}+2 \mathrm{OH}^{-}+22 \mathrm{H}_{2} \mathrm{O} \\
\rightarrow 3 \mathrm{CaO} \cdot \mathrm{Al}_{2} \mathrm{O}_{3} \cdot 3 \mathrm{CaSO}_{4} \cdot 32 \mathrm{H}_{2} \mathrm{O}
\end{aligned}
$$

$\mathrm{AFt}$ has a very low ion product $\left(10^{-111.6}\right)$ [23], so formula (1) has a strong reaction tendency in a system where gypsum, GBFS and $\mathrm{Ca}(\mathrm{OH})_{2}$ all exist. With the continuous formation of AFt, the dissolution balance of meta-aluminate between the surface of glassy GBFS and the solution was constantly broken, which had promoted the alumi-

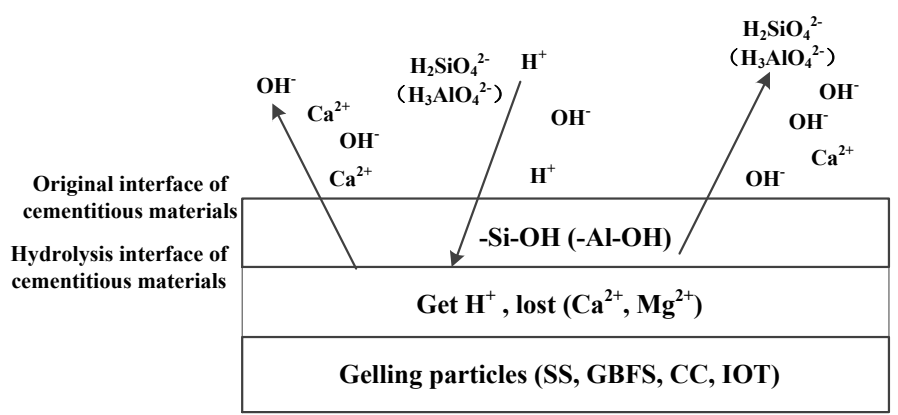

Figure 9. Hydration process model of cementitious materials for SIRSC

num-oxygen tetrahedra to constantly migrate from the surface of the glassy GBFS, destroying the connection between the silicon-oxygen tetrahedra and the aluminum-oxygen tetrahedra, making the degree of polymerization of the silicon (aluminum)-oxygen tetrahedra on the surface of the glassy GBFS decrease rapidly; the activity of residual silicon-oxygen tetrahedra and aluminum-oxygen tetrahedra was greatly improved, and C-S-H gels were constantly formed in the concrete slurry solution which was rich in $\mathrm{Ca}(\mathrm{Mg})^{2+}$. This type of reaction occurs not only on the surface of glassy GBFS particles, but also on the surface of low-crystallinity tailings particles and SS particles after their mechanical properties had been chemically activated. Therefore, in the gelling system containing a large amount of solid waste fine powders such as IOT, GBFS, SS, and FGDG, there is a synergistic generation process of AFt and C-S-H gels, and the growth of AFt is an obvious volume expansion process [24]. The volume of hardened slurry expanded due to the formation of ettringite, during this process, the solid phase volume of the ettringite increased due to the supplementation of external moisture, and the mutual repellent (under the condition of certain porosity) caused by the crystallization pressure of cross-growth of the crystals is the fundamental cause of the volume expansion, and the value of the volume expansion is related to the shape, quantity and formation time of AFt. The growth of C-S-H gels is often accompanied by the autogenous shrinkage of concrete [25], and the synergistic growth of AFt and C-S-H gels can greatly increase the strength of the concrete while reducing the autogenous shrinkage of the concrete.

In the coarse aggregate-free concrete prepared by such cementitious materials and raw grain-level IOT, the ratio of solid wastes in the concrete can reach $87 \%$, and its value of concrete autogenous shrinkage at $28 \mathrm{~d}$ during the curing process is far less than that of common RSC, so it had solved the problem of RSC prestress loss caused by excessive autogenous shrinkage of coarse aggregate-free IRSC.

\section{CONCLUSIONS}

(1) The addition of SS powder has a very significant effect on suppressing the autogenous shrinkage of RSC. At the age of $12 \mathrm{~h}$, the value of the concrete autogenous shrinkage was $112 \times 10^{-6}$; at the age of 28 
$\mathrm{d}$, this value of the concrete test pieces was $230 \times 10^{-6}$, which is significantly lower than that of ordinary RSC.

(2) Analysis of the hydration mechanism of the cementitious materials shows that a large amount of low-crystalline or amorphous C$\mathrm{S}-\mathrm{H}$ gels and a small amount of fibrous hydration product AFt had been formed in the early hydration stage. AFt crystals were mostly distributed in the voids and gaps, making the structure of the test blocks denser, the C-S-H gels were filled between the unreacted particles, so the dispersed particles were cemented into a dense whole. With the increase of the hydration age, the interlaced fiber-shaped C-S-H gels gradually grew into amorphous shape, and then became a network structure. At the same time, a large number of slender needle-shaped AFt crystals had been completely encapsulated and gelled, thereby the density of the structure of the entire system had been ensured.

(3) The hydration expansion of the $\mathrm{f}-\mathrm{CaO}$ and $\mathrm{f}-\mathrm{MgO}$ phases contained in SS was the main source of expansion for suppressing the autogenous shrinkage of the RSC. In the middle and late stages of concrete hardening, the synergistic growth of AFt and C-S-H gels in the system played an important role in suppressing the autogenous shrinkage and enhancing the strength of RSC in middle and later stages.

\section{ACKNOWLEDGMENTS}

The authors gratefully acknowledge financial support from China Postdoctoral Science Foundation (2016M602082), supported by Natural Science Foundation of Hebei Province (E2018402119), supported by Natural Science Foundation of Shaanxi Province (2019JLM-49), supported by Shaanxi Science and Technology Benefit People Project (2018ZY-HM-01), supported by Science and Technology Research Project of Higher Education Universities in Hebei Province (ZD2016014, QN2016115), supported by Comprehensive Utilization of Tailing Resources Key Laboratory of Shaanxi Province (2017SKYWK008), supported by Jiangxi Postdoctoral Daily Fund Project (2016RC30), supported by Jiangxi Postdoctoral Research Project (2017KY19), supported by State Key Laboratory of Solid Waste Reuse for Building Materials (SWR-2019-008).

\section{REFERENCES}

[1] Zhang C H, Liao J L, Ju J T, Dang Y J., Journal of Iron and Steel Research, 25(7), 1 (2013).

[2] Huang H., Fly Ash Comprehensive Utilization, 2, 51(2012).

[3] Teng S, Lim T Y D, Divsholi B S., Construction and Building Materials, 40, 875 (2013).

[4] Wang Q, Yan P Y, Feng J W., Journal of Hazardous Materials, 186(2-3), 1070 (2011).

[5] Wang Q, Yan P Y, Kong X M, Yang J B., Wuhan University of Technology-Materials Science Edition, 26(5), 998 (2011).

[6] Yan P Y, Wang Q., Journal of Tsinghua University (Science and Technology), 49(6), 790 (2009).

[7] Takashima K., Modification of steel making reducing slag, 11310441, Japan, 2011

[8] Yang G H, Guo J W, Wang J H., Mining Engineering, 2(8), 55 (2010).

[9] Lepage E, Balbaki M, Dallalre É, Aïtcin P C., Cement, Concrete and Aggreagtes, 21(2), 31 (1999).

[10]An M Z, Zhu J Q, Qin W Z., Journal of Building Materials, 4(2), 159 (2001)

[11]Zhou S X., Journal of East China Jiaotong University, 10(24), 13 (2007).

[12]Zheng Y C, Ni W, Xu L, Li D Z, Yang J H., Journal of University of Science and Technology Beijing, 32(4), 504 (2010).

[13]Shen W G, Zhou M K, Zhao Q L, Jiang Z Q, Zhou H L., Journal of
Wuhan University of Technology, 24(5), 15 (2002).

[14]Zhu W Q, He X W, Zhu J D, Yang W F. Xue W J., Journal of Wuhan University of Technology, 25(12), 116 (2003).

[15]Gao Y L, Zhou S Q, Ma B G., Journal of the China Railway Society, 28(3), 121 (2006).

[16]Sun J Y, Wang Z X., Journal Building Materials, 9(4), 477 (2006).

[17]Wang Q, Yan P Y., Construction and Building Materials, 24(7), 1134 (2010).

[18]Li Y, Bao J L, Guo Y L., Construction and Building Materials, 24, 1855 (2010).

[19]Yan P Y, Qin X, Yang W Y., Journal of the Chinese Ceramic Society, 28(4), 319 (2000).

[20]Mason B., Journal of Iron and Steel Institute, 179(11), 69 (1944).

[21]Cui X W, Ni W., Revista de la Facultad de Ingeniería, 31(7), 172 (2016).

[22]Cui X W, Ni W, Ren C., Chinese Journal of Materials Research, 31(9), 687 (2017).

[23]Myneni S C B, Traina S J, Logan T J., Chemical Geology, 148(12), 1 (1998).

[24]Altum I A, Yilmaz I., Cement and Concrete Research, 32(8), 1247 (2002).

[25]Li Y, Bao J L, Guo Y L., Construction and Building Materials, 24(10), 1855 (2010). 